\title{
SISTEM INFORMASI KELUHAN PELANGGAN BERBASIS WEBSITE
}

\author{
Sally Nurlita Zaman ${ }^{1 *}$, Nita Merlina ${ }^{2}$ Nurajijah $^{3}$ \\ 1-3 Sistem Informasi, Sekolah Tinggi Manajemen Informatika dan Komputer Nusa Mandiri \\ Indonesia \\ 1.
}

\begin{abstract}
Service to customers is an important aspect of the sustainability of a company. To provide satisfaction to customers requires loyalty in service implementation in order to create a good impression for the company. The increasingly tight business competition requires companies toalways provide improvements in every aspect. Ignoring a complaint not only wastes a golden opportunity, but it can also pose a threat to the company. So it can be realized that customer complaints are something that must be considered, as well as how we respond to customer complaints. This study aims to build a customer complaint information system by implementing a systematic, integrated, and measurable service. The customer complaint handling system implements the linear sequential development method (waterfall). The stages carried out are system requirements analysis, design, coding, and system testing. The resulting system can make it easier for customers to complain about the obstacles that occur and help the company respond to complaints systematically.
\end{abstract}

Keywords:Information Systems; Website, Customer Complaints

\begin{abstract}
Abstrak
Layanan terhadap pelanggan merupakan aspek penting dalam keberlangsungan suatu perusahaan. Untuk memberikan kepuasan terhadap pelanggan dibutuhkan loyalitas pada implementasi pelayanan agar tercipta kesan yang baik untuk perusahaan. Persaingan bisnis yang semakin ketat menuntut perusahaan untuk selalu memberikan perbaikan-perbaikan dalam setiap aspek. Mengabaikan komplain tidak hanya menyia-nyiakan kesempatan emas, tapi juga dapat menjadi ancaman bagi perusahaan. Maka dapat disadari bahwa komplain pelanggan adalah suatu hal yang harus diperhatikan, begitu juga bagaimana kita menanggapi komplain pelanggan tersebut. Penelitian ini bertujuan untuk membangun sistem informasi keluhan pelanggan dengan menerapkan pelayanan yang sistematis, terintegrasi, serta terukur. Sistem penanganan keluhan pelanggan mengimplementasikan metode pengembangan sekuensial linier (waterfall). Tahap yang dilakukan yaitu analisis kebutuhan sistem, desain, pengkodean dan uji sistem. Sistem yang dihasilkan dapat memudahkan pelanggan dalam menyampaikan keluhannya terhadap kendala yang terjadi dan membantu perusahaan dalam menanggapi keluhan secara sistematis.
\end{abstract}

Kata Kunci: Sistem Informasi; Website; Keluhan Pelanggan 


\section{Introduction}

Layanan terhadap pelanggan merupakan aspek penting dalam keberlangsungan suatu perusahaan. Untuk memberikan kepuasan terhadap pelanggan dibutuhkan loyalitas pada implementasi pelayanan agar tercipta kesan yang baik untuk perusahaan. Teknologi yang terus berkembang telah menjadikan pengembangan layanan untuk menangani keluhan pelanggan yang efektif dan efisien menjadi tantangan bagi organisasi. Mengabaikan komplain tidak hanya menyia-nyiakan kesempatan emas, tapi juga dapat menjadi ancaman bagi perusahaan. Komplain pelanggan adalah suatu hal yang harus diperhatikan, begitu juga bagaimana kita menanggapi komplain pelanggan tersebut.Penanganan komplain yang efektif dapat memiliki dampak dramatis pada tingkat retensi pelanggan, mencegah penyebaran negatif dari mulut ke mulut, dan meningkatkan kinerja perusahaan.Walaupun terlihat sederhana, dalam pelaksanaannya menangani komplain pelanggan merupakan hal yang kompleks dan perlu kehati-hatian. Perusahaan perlu menerapkan pelayanan pelanggan yang sistematis, terintegrasi, serta terukur. Metode penanganan komplain pelanggan secara manual dianggap sudah tidak relevan dengan di tengah kondisi teknologi informasi yang berkembang pesat ini. Komplain yang dilakukan pelanggan awalnya diinformasikan via telepon. Barang yang dikomplain akan dicek data administrasinya pada file di perusahaan.

Penelitian sebelumnya telah dilakukan (Saputra, 2016) menghasilkan aplikasi pengaduan yang dapat memudahkan mahasiswa menyampaikan pengaduan serta membantu fakultas atau prodi untuk mengawasi program studi dalam menanggapi pengaduan. Penelitian (Kusuma \& Yulianto, 2013) membuat sebuah website interaktif yang dapat membantu proses penyaluran informasi dan sebagai wadah untuk berinteraksi antara pelanggan dengan pihak PT. Telkom secara online. Penelitian (Setiawan, 2010) menyediakan layanan informasi keluhan yang dapat tersimpan di dalam database dan dapat memudahkan manajemen dalam mengelola informasi keluhan pelanggan secara maksimal.

Berdasarkan permasalahan dan melihat penelitian yang pernah dilakukan sebelumnya maka diperlukan sistem yang dapat memudahkan dalam penanganan keluhan pelanggan berbasis web ( $R$. Hidayat, n.d.). Penelitian ini bertujuan membuat sistem informasi (Rohman \& Aminaa, 2018)yang yang mampu menampung komplain secara online, mencatat kemajuan penanganan, mencatat dan menampilkan tanggapan, serta memudahkan administrator dalam membuat 
laporan dan dokumentasi. Sehingga proses penanganan komplain dapat menjadi lebih cepat, sehingga proses penanganan komplain dapat menjadi lebih cepat, dan lebih efektif karena pihak-pihak yang bertanggung jawab untuk menangani komplain tersebut dapat mengakses informasi yang dibutuhkan secara bersamaan.

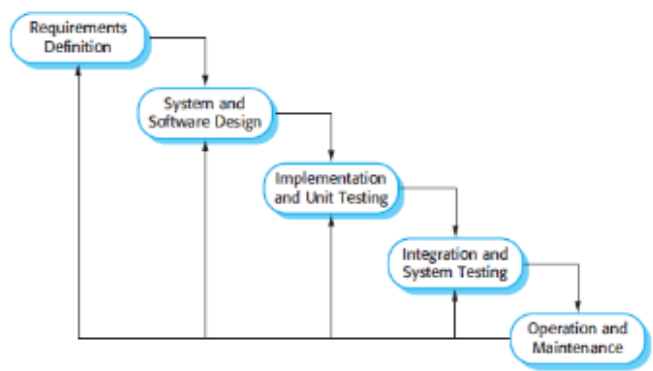

(Sumber: Dermawan, et al., 2019) Gambar 1 Metode Waterfall

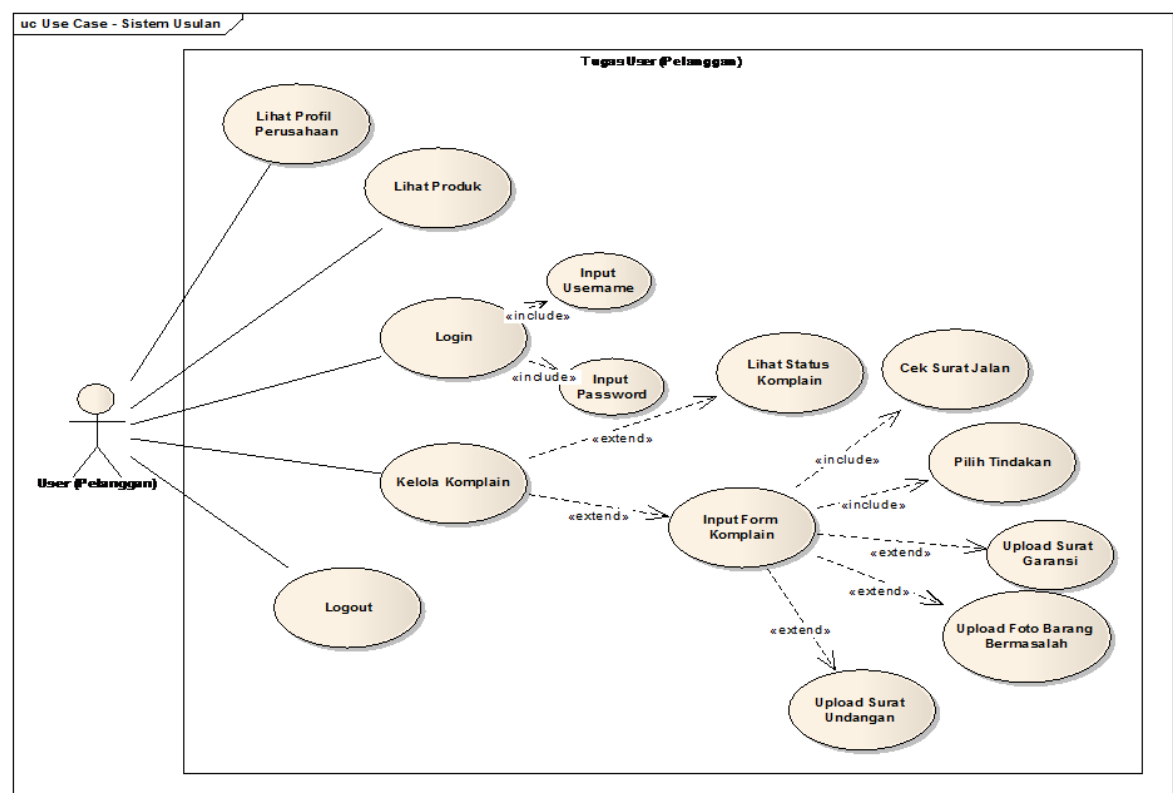

Gambar 2. Usecase Diagram Pelanggan 


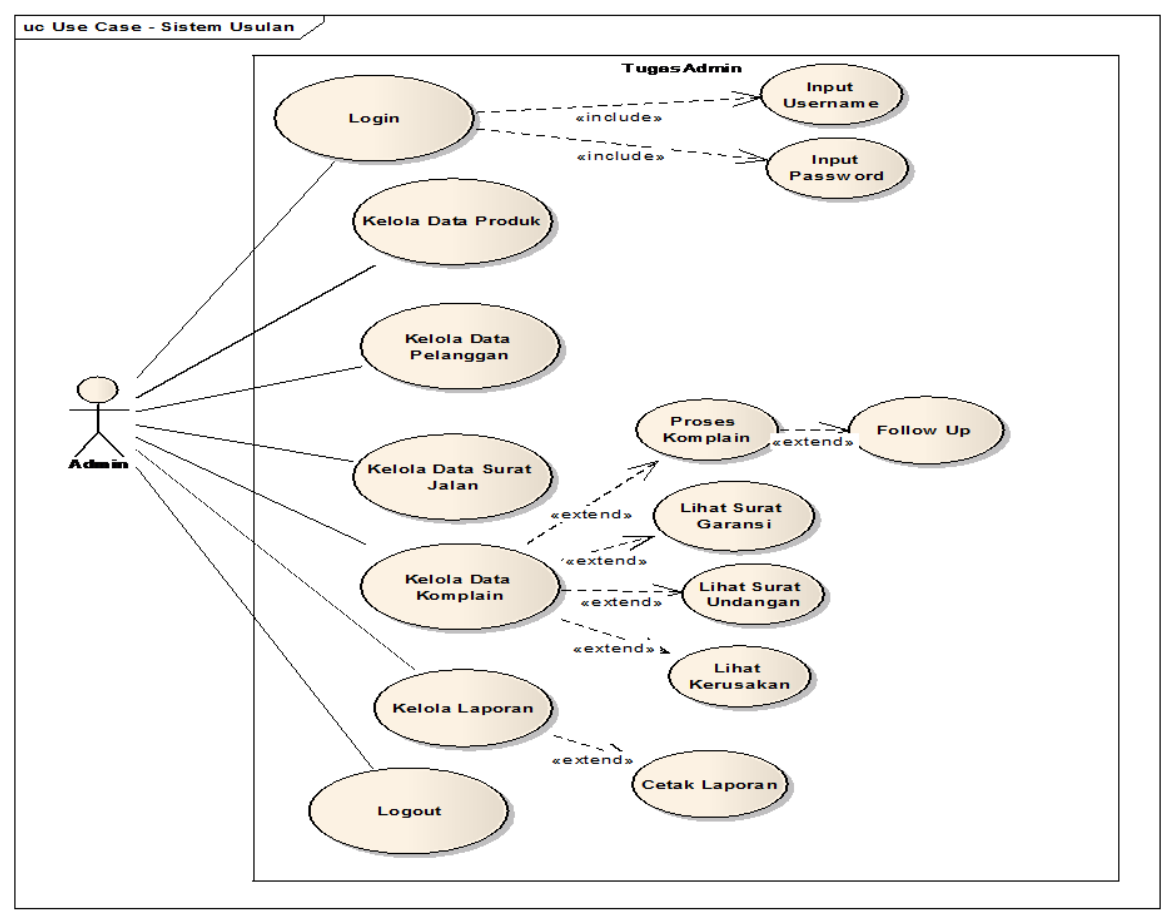

Gambar 3. Usecase Diagram Admin

\section{Material and Method}

Metode pengembangan sistem yang digunakan adalah metode sekuensial linier atau waterfall(Nurajijah \& Indriani, 2017)(Sundari, 2016) yaitu model yang menyediakan pendekatan alur hidup perangkat lunak secara sekuensial atau berurutan dimulai dari analisis, desain, pengkodean, pengujian dan tahap pendukung seperti pada gambar 1 . 


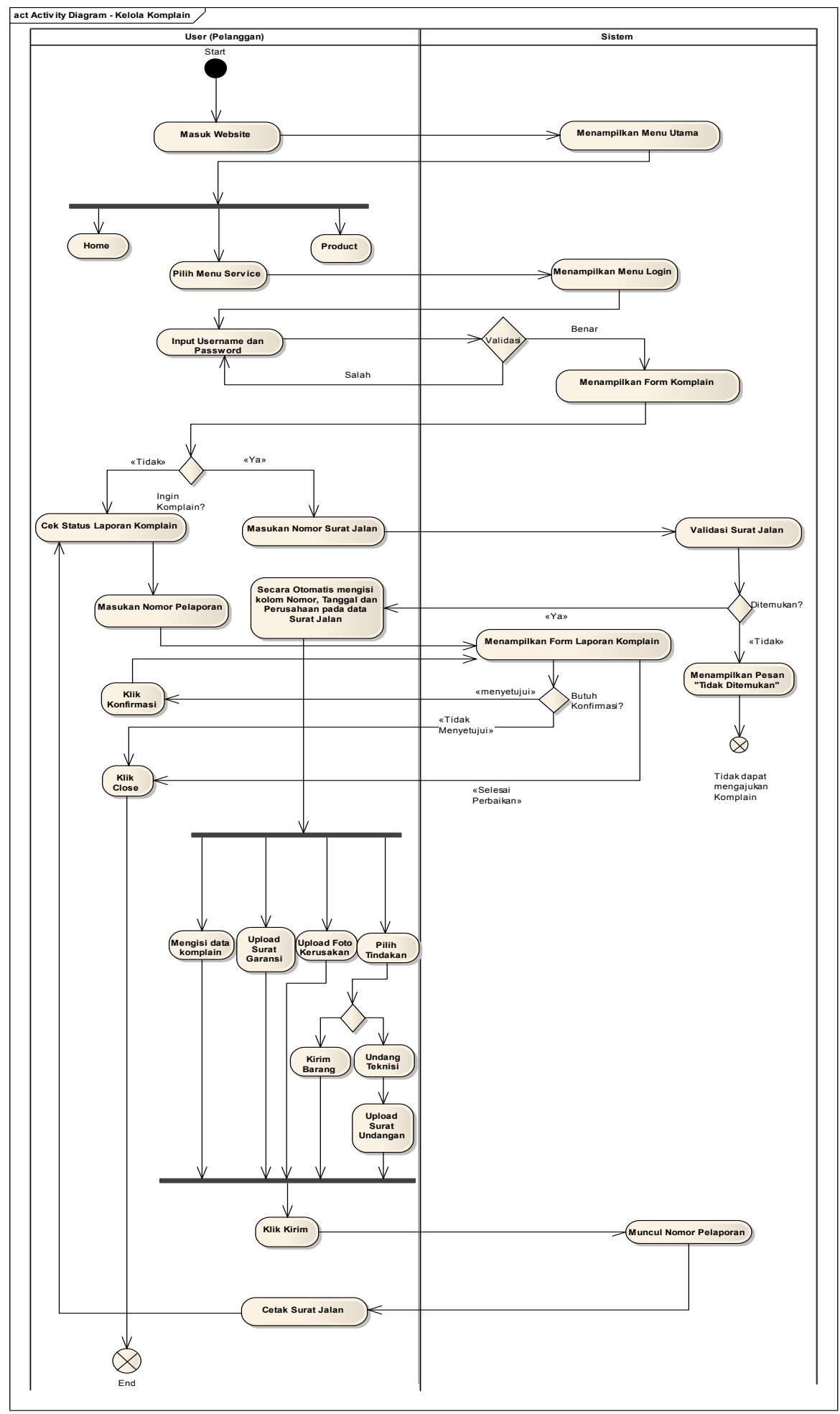

Gambar 4. Activity Diagram Pelaporan Komplain 


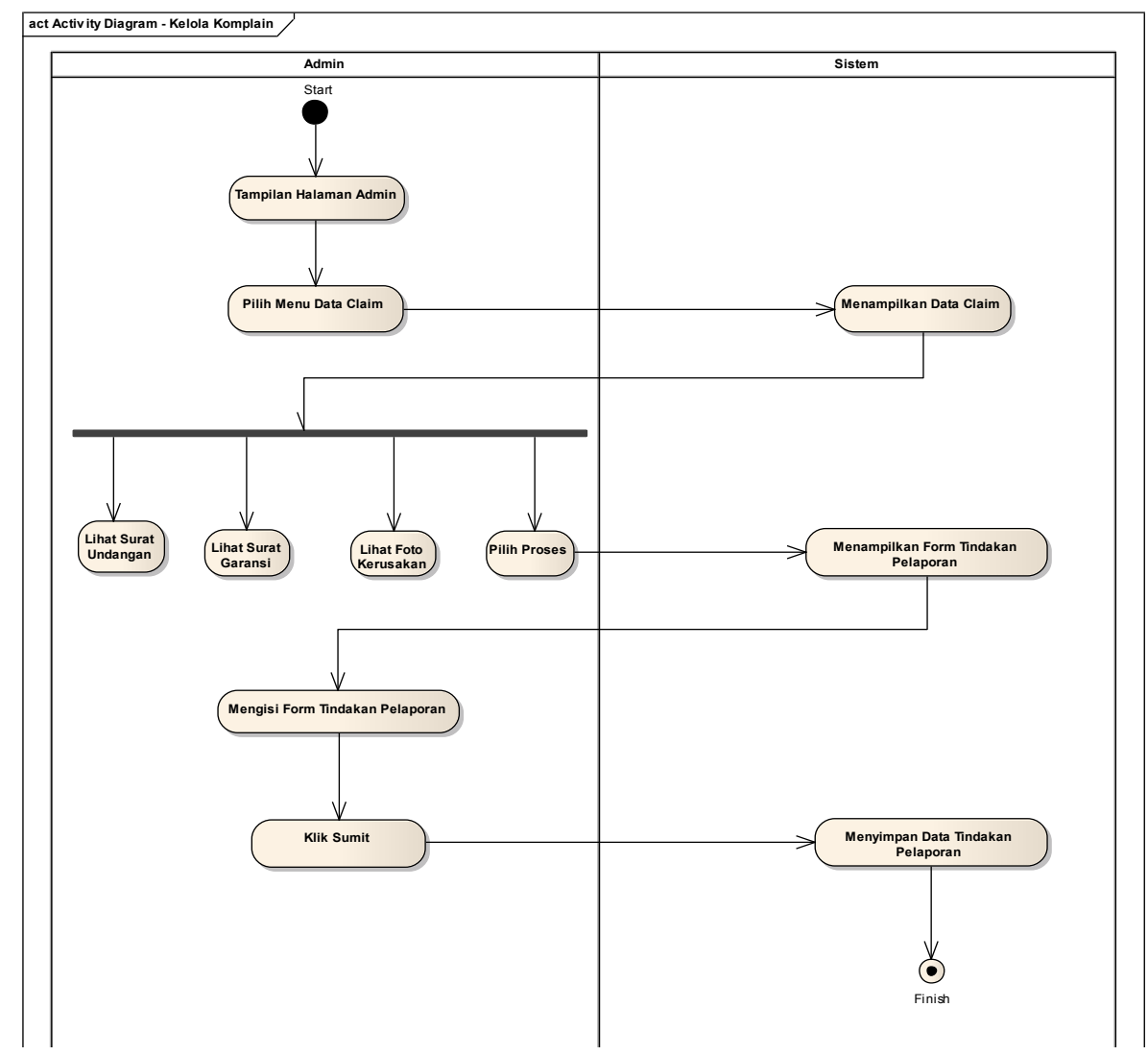

Gambar 5. Activity Diagram Kelola Komplain

\subsection{Analisa Kebutuhan Software}

Terdapat kebutuhan terhadap penggunaan Sistem yaitu Pelanggan dapat mengajukan keluhan secara online dan admin dapat memprosesnya, serta mencetak laporan keluhan.

\subsection{Desain}

Tahap desain dibutuhkan sebagai proses multi langkah yang fokus pada desain pembuatan program aplikasi(Yusma et al., 2021).Kebutuhan terhadap sistem yang digambarkan melalui usecase untuk masing - masing actor. Pada Gambar 2 pelanggan dapat melihat profil perusahaan dan produk, serta setelah login dapat melakukan keluhan secara online. Sedangkan pada Gambar 3 admin dapat memproses keluhan, melihat dan mencetak laporan keluhan, serta mengelola data produk dan pelanggan.

Aktivitas setiap user terhadap sistem digambarkan dalam Activity Diagram seperti pada Gambar 4 yaitu pelanggan dapat melakukan komplain setelah login dan dapat memantau proses tersebut. Gambar 5 menjelaskan Admin dapat melakukan login dan mengelola komplain pelanggan. Menggambarkan tata letak sistem secara fisik lewat Deployment Diagram, yang menampakkan bagian-bagian software yang berjalan pada hardware yang digunakan untuk mengimplementasikan sebuah sistem dan keterhubungan antara

\section{Sedangkan pada Gambar 3 admin dapat}


komponen hardware-hardware tersebut pada gambar 6 .

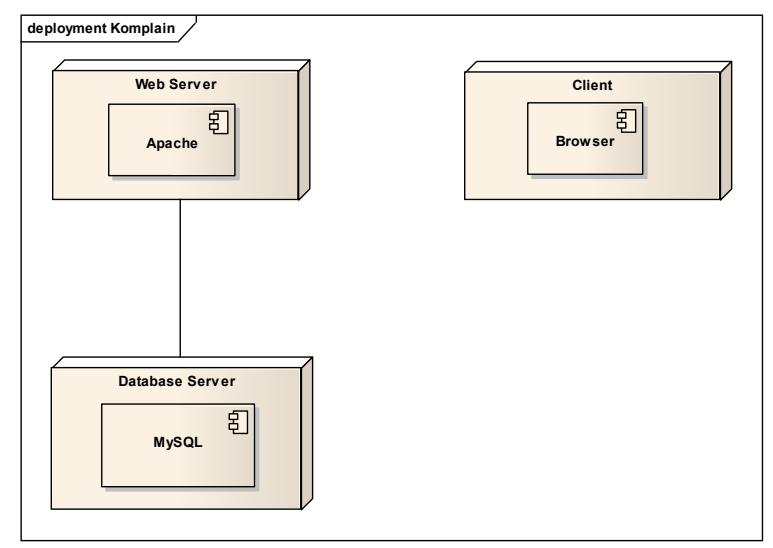

Gambar 6. Deployment Diagram

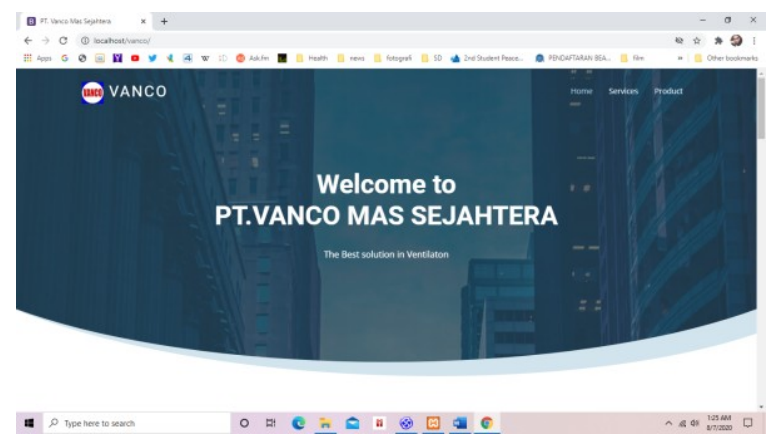

Gambar 7. Halaman Beranda

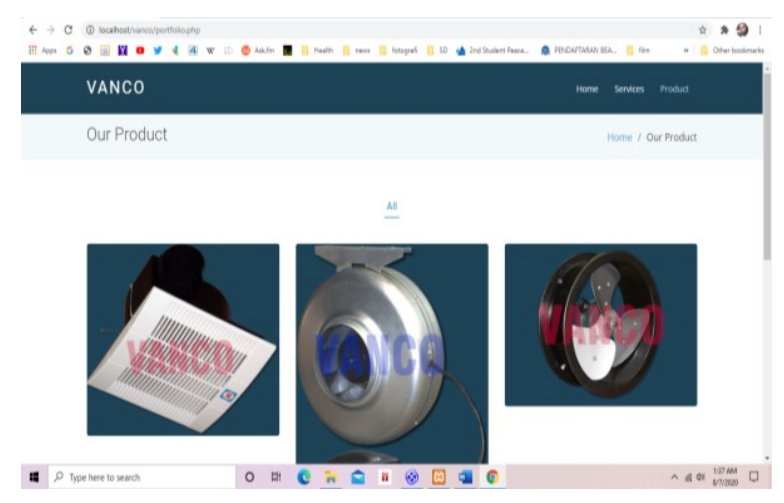

Gambar 8. Halaman Produk

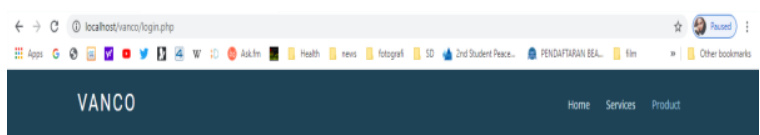

Layanan Pelaporan Keluhan pelanggan

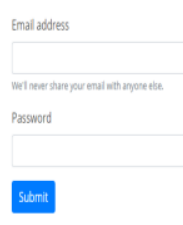

Gambar 9. Halaman Login Pelanggan

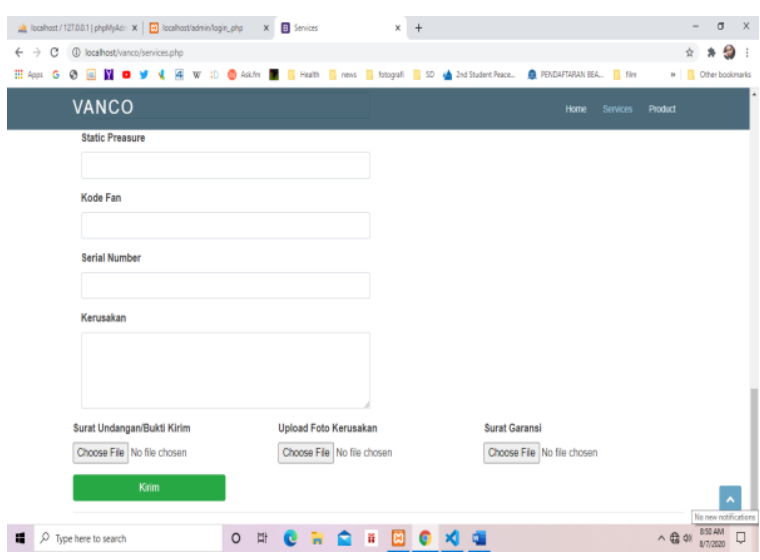

Gambar 10. Halaman service untuk claim keluhan

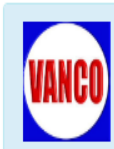

1 username or email

- password

Login

\section{Results and Discussion}

Pengimplementasian desain yang telah dibuat untuk merancang sistem informasi keluhan pelanggan berbasis web dengan menggunakan bahasa pemrograman $\mathrm{PHP}(\mathrm{H}$. Hidayat et al., 2017) serta menggunakan 
Visual Studio Code sebagai source-code editor dan database MySQL(Nofyat et al., 2018). Halaman beranda pada gambar 7 merupakan halaman awal dalam website, pada halaman beranda ini terdapat profil perusahaan. Halaman produk pada gambar 8 memberi informasi produk yang tersedia. User atau admin dapat login pada form loginpada gambar 9 agar dapat mengakses Komplain (Claim).Pelanggan dapat melaporkan keluhannya dengan mengisi dan mengupload dokumen terkait keluhan pada halaman servicegambar 10. Admin login pada halaman pada gambar 11 agar dapat mengakses Data Claim, Laporan Pelanggan, Surat Jalan, Master Pelanggan dan Master Produk. Pada form Data Claim gambar 12 admin dapat memproses keluhan pelanggan. Laporan data keluhan pelanggan dapat dilihat pada gambar 13 .

Sistem penanganan keluhan pelanggan dilakukan pengujian menggunakan metode black box testing untuk meminimalisir kesalahan (error) pada hasil input dan output sesuai dengan yang diinginkan. Hasil pengujian dapat dilihat pada Tabel 1. Tabel 1 menunjukan bahwa sistem penangan keluhan pelanggan yang dirancang sudah sesuai dengan yang diharapkan.

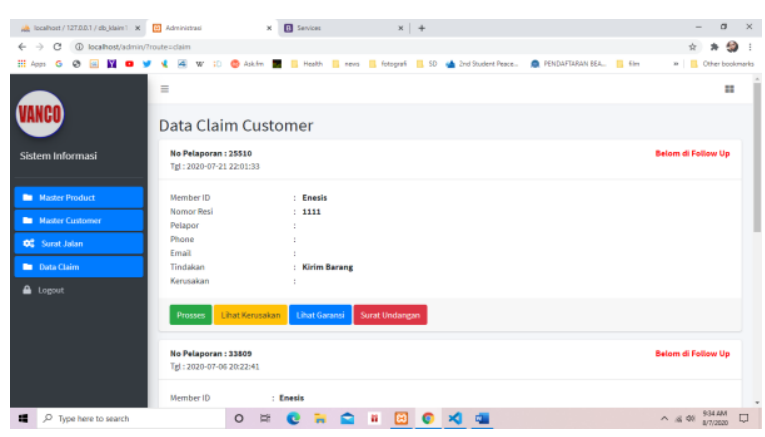

Gambar 12. Halaman Admin proses keluhan pelanggan

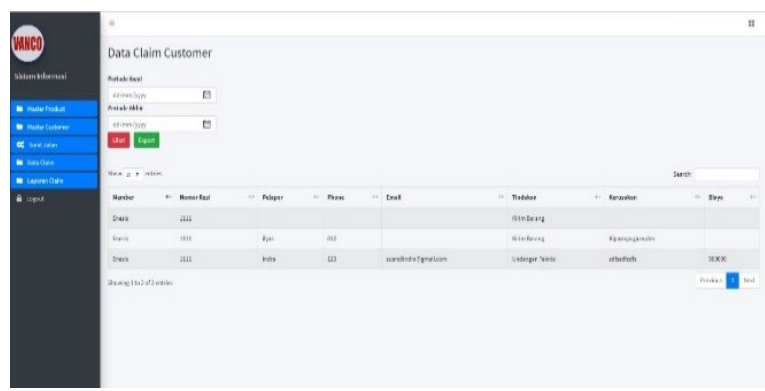

Gambar 13. Halaman Data Laporan Claim

Tabel 1. Hasil Pengujian

\begin{tabular}{|c|c|c|c|c|}
\hline $\begin{array}{l}\mathbf{N} \\
\mathbf{0}\end{array}$ & $\begin{array}{c}\text { Skenario } \\
\text { pengujian }\end{array}$ & $\begin{array}{l}\text { Test } \\
\text { Case }\end{array}$ & $\begin{array}{l}\text { Hasil Yang } \\
\text { Diharapkan }\end{array}$ & $\begin{array}{l}\text { Hasil } \\
\text { Pengu } \\
\text { jian }\end{array}$ \\
\hline 1 & $\begin{array}{l}\text { Username dan } \\
\text { Password tidak } \\
\text { diisi lalu klik } \\
\text { tombol "login" }\end{array}$ & $\begin{array}{l}\text { Username: } \\
\text { (kosong) } \\
\text { Password: } \\
\text { (kosong) }\end{array}$ & $\begin{array}{l}\text { Sistem akan } \\
\text { menolak akses } \\
\text { login dan kembali } \\
\text { ke tampilan form } \\
\text { login }\end{array}$ & $\begin{array}{l}\text { Sesuai } \\
\text { harapan }\end{array}$ \\
\hline 2 & $\begin{array}{l}\text { Hanya mengisi } \\
\text { data username } \\
\text { dan } \\
\text { mengosongkan } \\
\text { password, lalu } \\
\text { klik tombol } \\
\text { "login" }\end{array}$ & $\begin{array}{l}\text { Username: } \\
\text { (admin) } \\
\text { Password: } \\
\text { (kosong) }\end{array}$ & $\begin{array}{l}\text { Sistem akan } \\
\text { menolak akses } \\
\text { login dan kembali } \\
\text { ke tampilan form } \\
\text { login }\end{array}$ & $\begin{array}{l}\text { Sesuai } \\
\text { harapan }\end{array}$ \\
\hline $\begin{array}{l}3 \\
.\end{array}$ & $\begin{array}{l}\text { Hanya mengisi } \\
\text { data password } \\
\text { dan } \\
\text { mengosongkan } \\
\text { username, lalu } \\
\text { klik tombol } \\
\text { "login" }\end{array}$ & $\begin{array}{l}\text { Username: } \\
\text { (kosong) } \\
\text { Password: } \\
\text { (admin) }\end{array}$ & $\begin{array}{l}\text { Sistem akan } \\
\text { menolak akses } \\
\text { login dan kembali } \\
\text { ke tampilan form } \\
\text { login }\end{array}$ & $\begin{array}{l}\text { Sesuai } \\
\text { harapan }\end{array}$ \\
\hline 4 & $\begin{array}{l}\text { Menginput } \\
\text { dengan kondisi } \\
\text { salah satu data } \\
\text { benar dan satu } \\
\text { lagi salah, lalu } \\
\text { klik tombol } \\
\text { "login" }\end{array}$ & $\begin{array}{l}\text { Username: } \\
\text { abcd } \\
\text { (salah) } \\
\text { Password: } \\
\text { abcd } \\
\text { (salah) }\end{array}$ & $\begin{array}{l}\text { Sistem akan } \\
\text { menolak akses } \\
\text { login dan kembali } \\
\text { ke tampilan form } \\
\text { login }\end{array}$ & $\begin{array}{l}\text { Sesuai } \\
\text { harapan }\end{array}$ \\
\hline 5 & $\begin{array}{l}\text { Menginput data } \\
\text { yang benar, lalu } \\
\text { klik tombol } \\
\text { "login" }\end{array}$ & $\begin{array}{l}\text { Username: } \\
\text { (admin) } \\
\text { Password: } \\
\text { (1) }\end{array}$ & $\begin{array}{l}\text { Sistem menerima } \\
\text { akses login }\end{array}$ & $\begin{array}{l}\text { Sesuai } \\
\text { harapan }\end{array}$ \\
\hline 6 & $\begin{array}{l}\text { Pengisian Form } \\
\text { Komplain } \\
\text { kemudian klik } \\
\text { "Kirim" }\end{array}$ & $\begin{array}{l}\text { Mengisi } \\
\text { form dan } \\
\text { upload } \\
\text { lampiran }\end{array}$ & $\begin{array}{l}\text { Sistem merecord } \\
\text { ke Data Klaim }\end{array}$ & $\begin{array}{l}\text { Sesuai } \\
\text { Harapan }\end{array}$ \\
\hline 7 & $\begin{array}{l}\text { Proses Klaim } \\
\text { dengan } \\
\text { mengklik } \\
\text { "Proses" }\end{array}$ & $\begin{array}{l}\text { Mengklik } \\
\text { "Proses" }\end{array}$ & $\begin{array}{l}\text { Siste } \\
\text { memunculkan } \\
\text { tampilan tindakan }\end{array}$ & $\begin{array}{l}\text { Sesuai } \\
\text { Harapan }\end{array}$ \\
\hline
\end{tabular}




\begin{tabular}{|c|c|c|c|c|}
\hline 8 & $\begin{array}{l}\text { Melihat laporan } \\
\text { dengan memilih } \\
\text { periode laporan } \\
\text { dan mengklik } \\
\text { "Lihat" }\end{array}$ & $\begin{array}{l}\text { Memilih } \\
\text { Periode } \\
\text { Awal dan } \\
\text { Periode } \\
\text { Akhir yang } \\
\text { akan } \\
\text { dilihat } \\
\text { kemudian } \\
\text { klik } \\
\text { "Lihat" }\end{array}$ & $\begin{array}{l}\text { Sistem } \\
\text { Memunculkan } \\
\text { Laporan Klaim } \\
\text { sesuai periode } \\
\text { yang ditentukan }\end{array}$ & $\begin{array}{l}\text { Sesuai } \\
\text { Harapan }\end{array}$ \\
\hline 9 & $\begin{array}{l}\text { Mencetak } \\
\text { Laporan dengan } \\
\text { mengklik } \\
\text { "Cetak" pada } \\
\text { form Laporan } \\
\text { Claim }\end{array}$ & $\begin{array}{l}\text { Klik } \\
\text { button } \\
\text { "Cetak" }\end{array}$ & $\begin{array}{l}\text { Laporan terunduh } \\
\text { berupa file format } \\
\text { xls }\end{array}$ & $\begin{array}{l}\text { Sesuai } \\
\text { Harapan }\end{array}$ \\
\hline
\end{tabular}

\section{Conclusions}

Setelah dilakukan pengujian terhadap sistem, sistem telah sesuai dengan yang diharapkan dan tidak terjadi kesalahan. Sistem informasi keluhan pelanggan berbasis web memudahkan pelanggan dalam menyampaikan keluhannya terhadap kendala yang terjadi dengan akses yang lebih fleksibel serta menambah efisiensi waktu penanganan keluhan dari pihak perusahan.Sistem informasi keluhan pelanggan berbasis website ini memiliki kelemahan atau kekurangan yaitubeberapa form yang seharusnya tidak perlu penginputan yang mana nantinya masih akan terjadi human error. Sebaiknya penginputan data tidak terlalu banyak dan lebih banyak menggunakan otomatisasi.

\section{References}

Hidayat, H., Hartono, \& Sukiman. (2017).

Pengembangan Learning Management System (LMS) untuk Bahasa Pemrograman PHP. Jurnal Ilmiah Core
IT: Community Research Information Technology, 5(1), 20-29.

Hidayat, R. (n.d.). Cara Praktis Membangun Website Gratis. Elex Media Komputindo.

Kusuma, A. B., \& Yulianto, L. (2013).

Pembuatan Website Monitoring

Keluhan Pelanggan Pada PT. Telkom

Unit Layanan Ngadirojo. Indonesia

Journal on Networking and Security, 3(4), 1-9.

Nofyat, Ibrahim, A., \& Ambarita, A. (2018).

Sistem Informasi Pengaduan Pelanggan

Air Berbasis Website Pada Pdam Kota

Ternate. IJIS - Indonesian Journal On

Information System, 3(1).

https://doi.org/10.36549/ijis.v3i1.37

Nurajijah, \& Indriani, K. (2017).

Implementasi Model Waterfall Pada

Pembangunan Sistem Informasi

Akademik Berbasis Web Pada Smk

Yapipa Serpong Utara. TECHNO Nusa

Mandiri, $\quad$ 14(2), 77-82.

http://ejournal.nusamandiri.ac.id/ejurna

1/index.php/techno/article/view/480

Rohman, H., \& Aminaa, T. N. (2018).

Perancangan Sistem Informasi

Pelaporan Posyandu Lansia. Jurnal Manajemen Informasi Dan Administrasi Kesehatan (J-MIAK), 01(02), 1-6.

Saputra, G. (2016). Pengembangan Sistem Penanganan Keluhan Berbasis Web 
(Studi Kasus: Fakultas Teknik

Universitas Muhammadiyah

Yogyakarta). In Tugas Akhir.

Setiawan, R. A. (2010). Sistem Informasi

Pengaduan Keluhan Pelanggan

Berbasis Web pada PT.PLN (Persero)

Ap.Denpasar - Bali. STIKOM

Surabaya, 16(1), 1689-1699.

https://doi.org/10.1017/CBO97811074

15324.004

Sundari, J. (2016). Sistem Informasi

Pelayanan Puskesmas Berbasis Web.

IJSE - Indonesian Journal on Software

Engineering.

Yusma, D., Merlina, N., \& Nurajijah. (2021). Sistem Informasi Pencarian Rumah Kost Berbasis Web. INTI NUSA MANDIRI, 15(2), 9-16. https://doi.org/https://doi.org/10.33480/ inti.v15i2.1702 VOL. 